\title{
Aberrant Promoter Hypomethylation of Sortilin 1: A Moyamoya Disease Biomarker
}

\author{
Hye Youn Sung, ${ }^{\mathrm{a}}$ Ji Yeoun Lee, ${ }^{\mathrm{b}, \mathrm{c}}$ Ae Kyung Park, ${ }^{\mathrm{d}}$ Youn Joo Moon, ${ }^{\mathrm{c}}$ Inho Jo, ${ }^{\mathrm{e}}$ Eun-Mi Park, \\ Kyu-Chang Wang, ' Ji Hoon Phi, Jung-Hyuck Ahn, ${ }^{\text {a }}$ Seung-Ki Kim ${ }^{\mathrm{c}}$ \\ aDepartment of Biochemistry, Ewha Womans University College of Medicine, Seoul, Korea \\ bDepartment of Anatomy, Seoul National University College of Medicine, Seoul, Korea \\ 'Division of Pediatric Neurosurgery, Seoul National University Children's Hospital, Seoul National University College of Medicine, Seoul, Korea \\ ${ }^{\mathrm{d} S}$ Suncheon National University College of Pharmacy, Suncheon, Korea \\ eDepartment of Molecular Medicine, Ewha Womans University College of Medicine, Seoul, Korea \\ fDepartment of Pharmacology, Ewha Womans University College of Medicine, Seoul, Korea
}

Background and Purpose The pathogenesis of moyamoya disease (MMD) remains poorly understood, and no reliable molecular biomarkers for MMD have been identified to date. The present study aimed to identify epigenetic biomarkers for use in the diagnosis of MMD.

Methods We performed integrated analyses of gene expression profiles and DNA methylation profiles in endothelial colony forming cells (ECFCs) from three patients with MMD and two healthy individuals. Candidate gene mRNA expression and DNA methylation status were further validated using reverse transcription-quantitative polymerase chain reaction (RT-qPCR) and pyrosequencing analysis of an expanded ECFC sample set from nine patients with MMD and ten controls. We evaluated the diagnostic accuracy of the potential biomarkers identified here using receiver operating characteristic curve analyses and further measured major angiogenic factor expression levels using a tube formation assay and RT-qPCR.

Results Five candidate genes were selected via integrated analysis; all five were upregulated by hypomethylation of specific promoter $\mathrm{CpG}$ sites. After further validation in an expanded sample set, we identified a candidate biomarker gene, sortilin 1 (SORT1). DNA methylation status at a specific SORT1 promoter $\mathrm{CpG}$ site in ECFCs readily distinguished patients with MMD from the normal controls with high accuracy (area under the curve 0.98, sensitivity $83.33 \%$, specificity 100\%). Furthermore, SORT1 overexpression suppressed endothelial cell tube formation and modulated major angiogenic factor and matrix metalloproteinase-9 expression, implying SORT1 involvement in MMD pathogenesis.

Conclusions Our findings suggest that DNA methylation status at the SORT1 promoter CpG site may be a potential biomarker for MMD.
Correspondence: Seung-Ki Kim Division of Pediatric Neurosurgery, Seoul National University Children's Hospital, Seoul National University College of Medicine, 101 Daehak-ro, Jongno-gu, Seoul 03080, Korea

Tel: +82-2-2072-3084

Fax: +82-2-744-8459

E-mail:nsthomas@snu.ac.kr

Co-correspondence: Jung-Hyuck Ahn Department of Biochemistry, Ewha Womans University College of Medicine, 1071 Anyangcheon-ro, Yangcheon-gu, Seoul 07985, Korea

Tel: +82-2-2650-5712

Fax: +82-2-2652-7846

E-mail:ahnj@ewha.ac.kr

Received: April 6, 2018

Revised: September 15, 2018

Accepted: September 18, 2018

Keywords Moyamoya disease; DNA methylation; Biomarkers; Diagnosis; Sortilin 1

Copyright $@ 2018$ Korean Stroke Society

This is an Open Access article distributed under the terms of the Creative Commons Attribution Non-Commercial License (http://creativecommons.org/licenses/by-nc/4.0/) which permits unrestricted non-commercial use, distribution, and reproduction in any medium, provided the original work is properly cited. 


\section{Introduction}

Moyamoya disease (MMD) is characterized by progressive bilateral occlusion of the terminal portion of the internal carotid arteries or the proximal portion of the anterior cerebral arteries and the middle cerebral arteries, and by the development of fine collateral networks near the stenotic lesions. ${ }^{1,2}$ While magnetic resonance imaging/angiography (MRI/MRA) are reliable tools for the diagnosis of MMD, cerebral angiography is the gold standard test. However, these imaging tools are either costly or invasive and are often not suitable for use in screening or follow-up applications. This is especially true for pediatric patients, who require sedation even for MRI/MRA. Furthermore, the complication risk associated with repeated puncture of the femoral arteries in children is not negligible. Therefore, the development of a noninvasive low-cost screening methods may aid in the clinical identification of MMD. The patient's family members may be screened first before follow-up with expensive invasive work-ups. Treated patients will, thus, require a reduced number of MRI/MRA or angiography assessments during the follow-up period.

Considering this background, research has focused on the identification of a biomarker for MMD, with recent molecular studies having suggested novel biomarker candidates in the serum and cerebrospinal fluid (CSF) of patients with MMD. Studies have also revealed differential plasma concentrations of various growth factors, cytokines, and angiogenic factors in patients with MMD compared with healthy controls. A study reported significantly elevated plasma concentrations of matrix metalloproteinase 9 (MMP-9), monocyte chemoattractant protein-1, interleukin-1 $\beta$, vascular endothelial growth factor (VEGF), and platelet-derived growth factor subunit B but lower plasma concentrations of MMP-3 and tissue inhibitors of metalloproteinase (TIMP)-1 and -2 in patients with MMD compared with the healthy controls. ${ }^{3}$ Furthermore, serum microRNA let-7c, alpha-1-antitrypsin, and MMP-9 may serve as potential biomarkers for MMD diagnosis. ${ }^{4-6}$ CSF cellular retinoic acid-binding protein-I, basic fibroblast growth factor (FGF), soluble vascular cell adhesion molecule 1, intercellular adhesion molecule 1, and E-selectin levels may also serve as MMD biomarkers. $^{7-9}$

Specific characteristics of circulating endothelial progenitor cells (EPCs) and smooth muscle progenitor cells (SPCs) may serve as potential biomarkers for MMD. For instance, a prior study reported high serum levels of circulating stromal cell-derived factor- $1 a$ and cluster of differentiation 34 (CD34)+/ C-X-C chemokine receptor type 4 (CXCR-4)+-EPCs in adult patients with MMD. ${ }^{10}$ In contrast, another study reported decreased levels of circulating EPCs in patients with MMD compared to the healthy controls. ${ }^{11}$ In addition, increased expression of genes involved in cell adhesion, cell migration, immune response, and vascular development, such as integrin $a 3$, brain-specific angiogenesis inhibitor 1 (BAl1)-associated protein 2-like 1, N-cadherin, ephrin (Eph) receptor $\mathrm{A} 5$, and melanoma cell adhesion molecule, have been detected in SPCs from patients with MMD. ${ }^{12}$ In recent genetic studies, ring finger protein 213 (RNF213) was also identified as an important MMD susceptibility gene in East Asian populations. ${ }^{13}$ An RNF213 variant (c. 14576G $>A$ ) was present in 95\% of the familial MMD cases and 79\% of the sporadic MMD cases. Additionally, this variant was strongly associated with early-onset and more severe forms of MMD, suggesting its use as a prognostic biomarker. However, the gene's function remains unconfirmed. ${ }^{13}$ Although several specific biomarkers have been suggested for MMD diagnosis and prognosis, to date, none have found utility in clinical practice.

Here, we investigated aberrant genome-wide $\mathrm{CpG}$ methylation patterns in endothelial colony forming cells (ECFCs) in patients with MMD compared to the healthy controls. To identify epigenetic biomarkers for MMD diagnosis, we further integrated $\mathrm{CpG}$ methylation and mRNA expression profiles to identify genes whose expression was regulated by DNA methylationdependent transcriptional modification. We observed that the expression of sortilin 1 (SORT1) was upregulated via hypomethylation of a specific $\mathrm{CpG}$ site in its promoter. Furthermore, the DNA methylation status at the specific promoter $\mathrm{CpG}$ site on SORT1 in ECFCs readily distinguished patients with MMD from normal controls with high accuracy. We propose that the DNA methylation status at a particular SORT1 promoter CpG site may be a biomarker for MMD.

\section{Methods}

\section{Study subjects}

Blood samples from patients with MMD and healthy controls were collected after informed consent was obtained from all participants according to a protocol approved by Seoul National University Hospital's Institutional Review Board (IRB) of (SNUH IRB 1404-006-567). All patients with MMD were diagnosed via cerebral angiography. For ethical reasons, recruitment of agematched controls was not possible; therefore, young adults with no history of stroke, hypertension, or smoking were chosen. Samples from 18 patients with MMD and 16 normal controls were used in the present study. We collected patient information, including sex, age, symptoms, Suzuki grade, and infarct specifics. The clinical characteristics of patients with MMD are summarized in the Supplementary Table 1. 


\section{Isolation and characterization of ECFCs}

The procedures for buffy coat preparation and mononuclear cell (MNC) culture priming towards an ECFC lineage have been described previously..$^{14}$ All blood samples $(40 \mathrm{~mL}$ ) were processed within 2 hours after collection. The MNCs were plated on culture dishes coated with collagen type I (BD BioCoat, BD Biosciences, Mountain View, CA, USA) in an endothelial cell growth medium (EGM-2, Clonetics, San Diego, CA, USA) with $10 \%$ fetal bovine serum (FBS). ECFCs were characterized by fluorescence-activated cell sorting (FACS) analysis and immunofluorescence staining using antibodies against CD34, kinase insert domain receptor (KDR), CD133, CD31, CD45, and von willebrand factor (vWF). For flow cytometry analyses, $1 \times 10^{6}$ cells were incubated for staining with $10 \mu \mathrm{L}$ each of phycoerythrin conjugated anti-human CD34 (BD Biosciences: Cata$\log$ \#555822), KDR (RCtD, Minneapolis, MN, USA: Catalog \#FAB357P), CD133 (Miltenyi biotec, Bergisch Gladbach, Germany: Catalog \#130-080-801), CD31 (BD Biosciences: Catalog \#560983), and CD45 (BD Biosciences: Catalog \#560975) antibodies. Resultant FACS data were analyzed using a FACScan flow cytometer (Becton Dickinson, Franklin Lakes, NJ, USA) and CellQuest software (Becton Dickinson). Immunofluorescent staining was performed using anti-CD31 (Santa Cruz Biotechnology, Dallas, TX, USA: Catalog \#sc-1506) and anti-vWF (DAKO, Glostrup, Denmark: Catalog \#M0616) antibodies.

\section{Cell culture}

Before human umbilical vein endothelial cells (HUVECs) isolation, written informed consent was obtained from each participant who donated an umbilical cord sample. The Ewha Womans University Mokdong Hospital IRB approved this study. HUVECs were isolated from fresh newborn umbilical cord veins by collagenase digestion using a standard protocol, as described previously. ${ }^{15}$ HUVECs were grown in Medium 200 supplemented with low serum growth supplements, 10\% FBS, and antibiotic-antimycotic (Gibco-BRL, Gaithersburg, MD, USA) at $37^{\circ} \mathrm{C}$ with $5 \% \mathrm{CO}_{2}$ in a humidified atmosphere. All experiments were conducted between the fourth and sixth cell passages.

\section{Total RNA isolation and mRNA microarray}

Total RNA was extracted from cultured cells using the RNeasy mini kit (Qiagen, Valencia, CA, USA) and amplified and labeled according to the Affymetrix GeneChip Whole Transcript Sense Target Labeling protocol (Thermo Fisher Scientific, Waltham, MA, USA). The resulting labeled complementary DNA (cDNA) was hybridized to Affymetrix Human Gene 2.0 ST Arrays (Thermo Fisher Scientific). Scanned raw expression values were background-corrected, normalized, and summarized using the
Robust Multiarray Averaging approach in the Bioconductor "affy" package (Bioconductor, http://www.bioconductor.org). The resulting $\log ^{2}$-transformed data were used for further analyses. To identify differentially expressed genes (DEGs), we used moderated t-statistics based on an empirical Bayesian approach. ${ }^{16}$ DEGs were defined as genes having expression levels in MMD samples that differed by at least a 1.5-fold (|fold change $(\mathrm{FC}) \mid>1.5)$ when compared with normal samples $(P<0.05)$.

\section{Genomic DNA isolation and $\mathrm{CpG}$ methylation microarray}

Genomic DNA was extracted from ECFCs using the OIAmp mini kit (Qiagen) according to the manufacturer's instructions. For genome-wide screening of DNA methylation, the Illumina HumanMethylation450 BeadChip (Illumina, San Diego, CA, USA) platform was used, which targets 450,000 specific $\mathrm{CpG}$ sites. To adjust for probe design bias, $\beta$-values were normalized based on the Beta Mixture Quantile method. ${ }^{17}$ Differentially methylated $\mathrm{CpG}$ sites were identified by moderated t-statistics. ${ }^{16} \mathrm{~A}$ differentially methylated $\mathrm{CpG}$ site was defined as having an average $\beta$-value that was significantly different in MMD samples compared to normal samples $(P<0.05$ and $|\Delta \beta|>0.2)$. We considered a $\mathrm{CpG}$ site as hypermethylated if $\Delta \beta$ was greater than 0.2 and as hypomethylated if $\Delta \beta$ was less than -0.2 .

\section{Reverse transcription-quantitative polymerase chain reaction}

One microgram of total RNA was converted to cDNA using Superscript II reverse transcriptase and oligo-(dT) 12-18 $_{18}$ primers (both from Thermo Fisher Scientific) according to the manufacturer's instructions. Reverse transcription-quantitative polymerase chain reaction (RT-qPCR) was performed using a $20-\mu \mathrm{L}$ reaction mixture containing $1 \mu \mathrm{L}$ cDNA, $10 \mu \mathrm{L}$ SYBR Premix EX Taq (Takara Bio, Otsu, Japan), $0.4 \mu \mathrm{L}$ 50x Rox reference dye (Takara Bio), and $200 \mathrm{nM}$ of gene-specific primers. The primer sequences used in this study are listed in the Supplementary Table 2. The reactions were run on a 7500 Fast Real-Time PCR System (Thermo Fisher Scientific) at $95^{\circ} \mathrm{C}$ for 30 seconds, followed by 40 cycles of $95^{\circ} \mathrm{C}$ for 3 seconds and $60^{\circ} \mathrm{C}$ for $30 \mathrm{sec}-$ onds and a single dissociation cycle of $95^{\circ} \mathrm{C}$ for 15 seconds, $60^{\circ} \mathrm{C}$ for 60 seconds, and $95^{\circ} \mathrm{C}$ for 15 seconds. All reactions were performed in triplicate, and the specificity of the reaction was determined using melting curve analyses at the dissociation stage. Comparative quantification of each target gene was performed based on the cycle threshold normalized to glyceraldehyde 3-phosphate dehydrogenase threshold using the $2^{-\Delta \Delta \mathrm{ct}}$ method. 


\section{Bisulfite sequencing PCR}

Treatment of the extracted genomic DNA from ECFCs with bisulfite converts unmethylated cytosines but not methylated cytosines to uracils, allowing for the distinction between unmethylated and methylated cytosines. DNA modification using bisulfite was performed using an EpiTech Bisulfite Kit (Qiagen) according to the manufacturer's instructions.

We performed bisulfite sequencing PCR (BSP) using conventional PCR in a $50 \mu \mathrm{L}$ reaction mixture containing $10 \mathrm{ng}$ of bisulfite-modified genomic DNA, $1.5 \mathrm{mM} \mathrm{MgCl} 2,200 \mu \mathrm{M}$ deoxynucleotide triphosphate, $1 \mathrm{U}$ Platinum Taq polymerase (Thermo Fisher Scientific), 1×Platinum Taq buffer, and $200 \mathrm{nM}$ specific BSP forward and reverse primers for each gene. BSP primers were designed using MethPrimer software (http://www.urogene.org/methprimer) (listed in Supplementary Table 3). The reaction ran at $95^{\circ} \mathrm{C}$ for 5 minutes followed by 30 cycles of $95^{\circ} \mathrm{C}$ for 30 seconds, $50^{\circ} \mathrm{C}$ to $55^{\circ} \mathrm{C}$ for 30 seconds, and $72^{\circ} \mathrm{C}$ for 30 seconds, and a final $72^{\circ} \mathrm{C}$ elongation step for 5 minutes. BSP products were purified using the OlAquick Gel Extraction kit (Qiagen), per the manufacturer's protocol, and ligated into a pGEM-T Easy cloning vector (Promega, Fitchburg, WI, USA). Ligation products were used to transform competent $\mathrm{DH} 5 \mathrm{a}$ Escherichia coli cells (RBC Bioscience, New Taipei City, Taiwan) using standard procedures. Blue/white screening was used to select bacterial clones, and BSP product-positive clones were confirmed by colony PCR using BSP primers to verify insert size. Plasmid DNA was then extracted from at least $10 \mathrm{in}$ sert-positive clones using the QIAprep Spin Miniprep Kit (Qiagen) and sequenced using M13 primers to analyze methylation status at specific $\mathrm{CpG}$ sites.

\section{5-aza-2'-deoxycytidine treatment}

ECFCs from normal control $\mathrm{N} 1$ were treated with the methylation inhibitor 5-aza-2'-deoxycytidine (Sigma-Aldrich, Darmstadt, Germany), which was replaced daily at various concentrations $(0,10$, and $20 \mu \mathrm{M})$ for 3 days.

\section{Pyrosequencing for DNA methylation analyses}

We used bisulfite pyrosequencing for methylation analyses of target promoter regions. Each primer was designed using the PSO assay design program (Qiagen) (sequences are listed in Supplementary Table 4). PCR reactions were performed in a volume of $20 \mu \mathrm{L}$ with $20 \mathrm{ng}$ or less of bisulfite-converted gDNA, $10 \mu \mathrm{L} 2 \times$ Hot/Start PCR premix (Enzynomics, Daejeon, Korea), $1 \mu \mathrm{L}$ forward primer (10 pmole/ $\mu \mathrm{L}$ ), and $1 \mu \mathrm{L}$ biotinylated-reverse primer (10 pmole/ $\mu \mathrm{L}$ ). Amplifications were performed according to general pyrosequencing guidelines involving denaturing at $95^{\circ} \mathrm{C}$ for 10 minutes, followed by 50 cycles at $95^{\circ} \mathrm{C}$ for 30 seconds, $56^{\circ} \mathrm{C}$ for 30 seconds, $72^{\circ} \mathrm{C}$ for 30 seconds, and a final extension of $72^{\circ} \mathrm{C}$ for 10 minutes. The PCR reaction $(2 \mu \mathrm{L})$ was confirmed by electrophoresis in a $2.5 \%$ agarose gel and visualized by ethidium bromide staining.

The ssDNA template was prepared from 16 to $18 \mu \mathrm{L}$ of biotinylated PCR product using streptavidin Sepharose HP beads (Amersham Biosciences, Piscataway, NJ, USA), following the PSO 96 sample preparation guide. Sequencing primers (15 pM) were then added for analyses. Sequencing was performed on a PyroMark ID system using the Pyro Gold reagent kit (Biotage, Uppsala, Sweden), per manufacturer's instructions. The analyzed sequences are listed in Supplementary Table 4.

\section{HUVEC transfection}

HUVECs were transfected with an enhanced green fluorescent protein (EGFP) or SORT1 expression construct using the Amaxa HUVEC Nucleofector kit (Lonza, Basel, Switzerland). Briefly, cells grown to $80 \%$ to $90 \%$ confluence were trypsinized and pelleted, and $5 \times 10^{5}$ cells were resuspended with $2.0 \mu \mathrm{g}$ of plasmid DNA (pCMV6-XL5-SORT1, Origene, Rockville, MD, USA) or pmaxGFP vector and $100 \mu \mathrm{L}$ of Nucleofector solution in a Nucleofection cuvette, using program U001. We then added $500 \mu \mathrm{L}$ of complete growth media and suspended the cells for 24 hours. Overexpression of SORT1 was confirmed by RT-qPCR 24 hours after transfection.

Pre-designed small interfering RNA (siRNA) against SORT1 (siSORT1, CAT\#ID L-010620-00-0005) and a non-targeting control siRNA (siNC, CAT\#ID D-001810-10-05) were purchased from Thermo Fisher Scientific. To deplete endogenous SORT1 expression, HUVEC were transfected with $100 \mathrm{nM}$ siSORT1 or siNC using DharmaFECT 4 transfection reagent (Thermo Fisher Scientific) according to the manufacturer's protocol. Knockdown of SORT1 mRNA was confirmed by RT-qPCR 24-hour post-transfection.

\section{Tube formation}

Tube formation was assessed via Matrigel assay. Basement membrane matrix Matrigel was purchased from BD Biosciences (Billerica, MA, USA). Matrigel was thawed on ice overnight and spread evenly over each well $(300 \mu \mathrm{L})$ of a 24 -well plate. Plates were then incubated for 1 hour at $37^{\circ} \mathrm{C}$ to allow the Matrigel to polymerize. Expression construct-transfected HUVECs were seeded at $4 \times 10^{4}$ cells per well on a Matrigel-coated 24-well plate and grown in $300 \mu \mathrm{L}$ of complete growth media for 16 hours in a humidified $37^{\circ} \mathrm{C}, 5 \% \mathrm{CO}_{2}$ incubator.

To determine the effect(s) of knockdown of endogenous SORT1 on tube formation, HUVECs transfected with either siSORT1 or siNC were cultured for 24 hours and then starved for 8 hours with Medium 200. After starvation, siRNA-transfected HUVECs 
Table 1. Differentially expressed genes with differentially methylated $\mathrm{CpG}$ sites in endothelial colony forming cells from patients with moyamoya disease

\begin{tabular}{|c|c|c|c|c|c|c|c|c|}
\hline \multicolumn{2}{|c|}{ Direction of change } & \multirow[b]{2}{*}{ Gene symbol } & \multicolumn{2}{|c|}{ Illumina Beadchip 450K } & \multicolumn{2}{|c|}{ Expression change } & \multicolumn{2}{|c|}{ Methylation change } \\
\hline Expression & Methylation & & $\begin{array}{c}\text { Target ID (Illumina } \\
450 \mathrm{~K})\end{array}$ & $\begin{array}{l}\text { UCSC RefGene } \\
\text { group* }\end{array}$ & Fold change & $P$ & $\Delta \beta$ & $P$ \\
\hline \multirow[t]{7}{*}{ Up } & Нypo & $A P O D$ & $\operatorname{cg} 05624196$ & $5^{\prime} \mathrm{UTR}^{+}$ & 1.39 & 0.040 & -0.38 & 0.050 \\
\hline & & & $\operatorname{cg} 23720929$ & 1st Exon & 1.39 & 0.040 & -0.43 & 0.002 \\
\hline & & FAP & $\operatorname{cg} 04793527$ & 5'UTR & 1.40 & 0.009 & -0.63 & 0.004 \\
\hline & & & cg08826839 & TSS200 & 1.40 & 0.009 & -0.52 & 0.029 \\
\hline & & LITAF & cg02051924 & TSS1500 & 2.43 & 0.000 & -0.23 & 0.007 \\
\hline & & NUPR1 & $\operatorname{cg} 04492847$ & TSS200 & 1.28 & 0.013 & -0.21 & 0.033 \\
\hline & & SORT1 & $\operatorname{cg} 23616212$ & TSS1500 & 1.72 & 0.022 & -0.36 & 0.027 \\
\hline
\end{tabular}

UCSC, University of California, Santa Cruz; APOD, apolipoprotein D; 5'UTR, $5^{\prime}$ untranslated region; FAP, fibroblast activation protein alpha; TSS, transcriptional start site; LITAF, lipopolysacchride induced tumor necrosis factor-alpha factor; NUPR1, nuclear protein 1; SORT1, sortilin 1.

*UCSC RefGene Group: gene region feature category describing the CpG position, from UCSC, as follows (TSS200 refers to 0-200 bases upstream of the TSS, TSS1500 refers to 200-1500 bases upstream of the TSS); ${ }^{+} 5$ 'UTR refers to within the 5 ' untranslated region, between the TSS and the ATG start site.

were plated at $1 \times 10^{5}$ cells per well on a Matrigel-coated 24-well plate using growth factor reduced Matrigel matrix (BD Biosciences) and grown for 6 hours to induce tube networking.

Tube-like structures were observed using a light microscope and camera at $40 \times$ magnification. Tube length was measured in six randomly selected fields per well and quantified by Image J software (http://rsb.info.nih.gov/ij/index.html).

\section{RNF213 gene sequencing}

DNA samples were obtained from ECFCs using the DNA Mini kit (Thermo Fisher Scientific), per manufacturer instructions. After DNA extraction and quantification, DNA samples were subjected to PCR amplification with the appropriate primer sets (sense 5'-CTGATGCGTCAGCTCCATAG-3' and antisense 5 '-TCCTGCTTGTGCAGTCAC- $3^{\prime}$ ). Sequencing analysis of the RNF213 c. $14576 \mathrm{G}>\mathrm{A}$ variant was conducted using a $\mathrm{ABI}$ 3730XL DNA sequencer, and data were analyzed by $A B I$ sequencing analysis software (Thermo Fisher Scientific).

\section{Statistical analyses}

All data are expressed as the mean \pm standard deviation (SD) of at least three independent experiments. Statistical analyses were done using GraphPad Prism 5 software (GraphPad Software Inc, La Jolla, CA, USA). Details of each analysis are provided in the figure legends. $P$-values $<0.05$ were considered statistically significant.

\section{Results}

\section{Selection of MMD-associated genes using integrated analysis}

We performed expression microarray and DNA methylation mi-
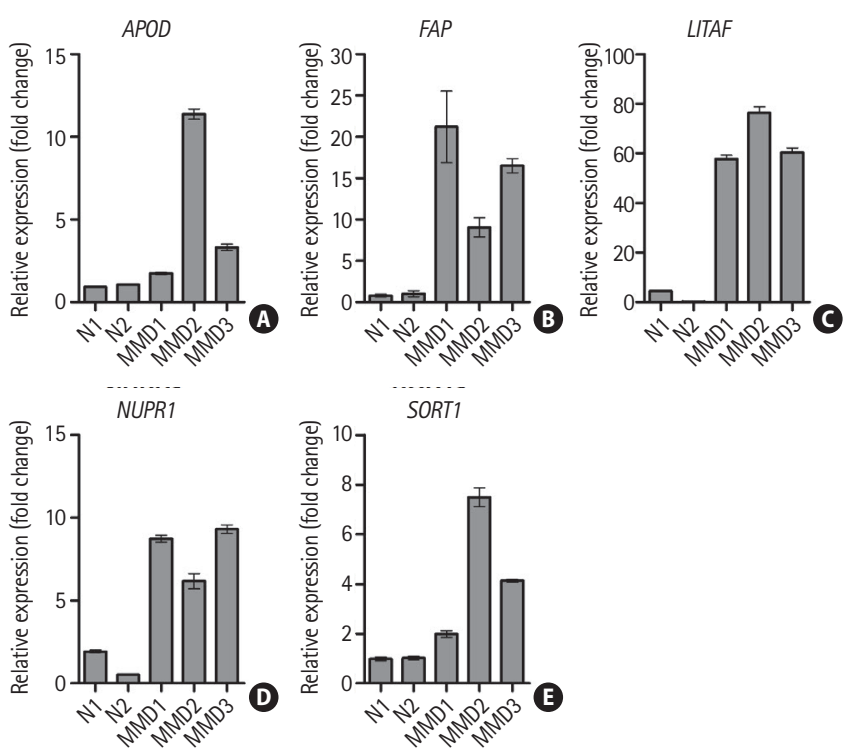

Figure 1. Upregulation of five candidate genes in endothelial colony forming cells from patients with moyamoya disease (MMD). mRNA expression for five candidate genes was determined by reverse transcription-quantitative polymerase chain reaction. Data are represented as the mean \pm standard deviation of three experiments. (A) Apolipoprotein D (APOD), (B) fibroblast activation protein alpha $(F A P)$, (C) lipopolysacchride induced tumor necrosis factor-alpha factor (LITAF), (D) nuclear protein 1 (NUPR1), and (E) sortilin 1 (SORT1). N, normal control.

croarray analyses in ECFCs from three patients with MMD (MMD1, MMD2, MMD3) and two normal controls (N1, N2), then selected DEGs and differentially methylated promoter $\mathrm{CpG}$ sites. To identify genes with differential expression that might be ascribed to changes in promoter $\mathrm{CpG}$ methylation, DNA methylation profiling data was integrated with mRNA expression profiling data using the following selection criteria: upregulated ( $\mathrm{FC}>1.5$ ) by hypomethylation $(\Delta \beta<-0.2)$ at pro- 
APOD1 (ch3: 195,583,895-195,584,362)

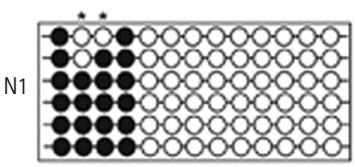

N2

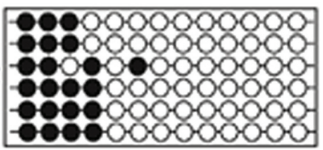

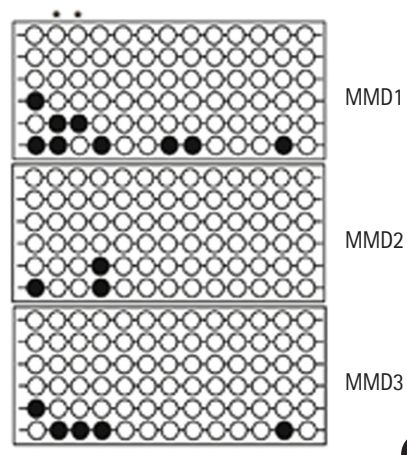

MMD3

A

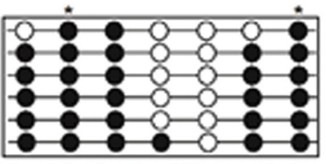

N2

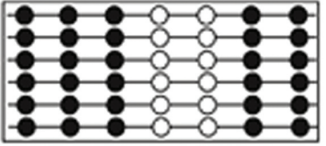

FAP(ch2: 162,243,202-162,243,697)

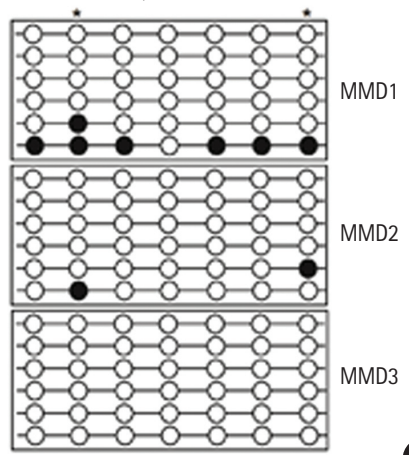

B
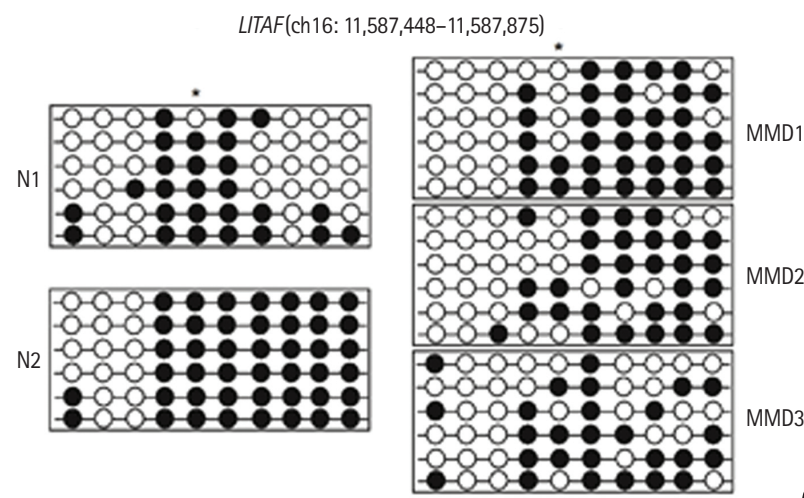

NUPR1 (ch16: 28,538,953-28,539,381)
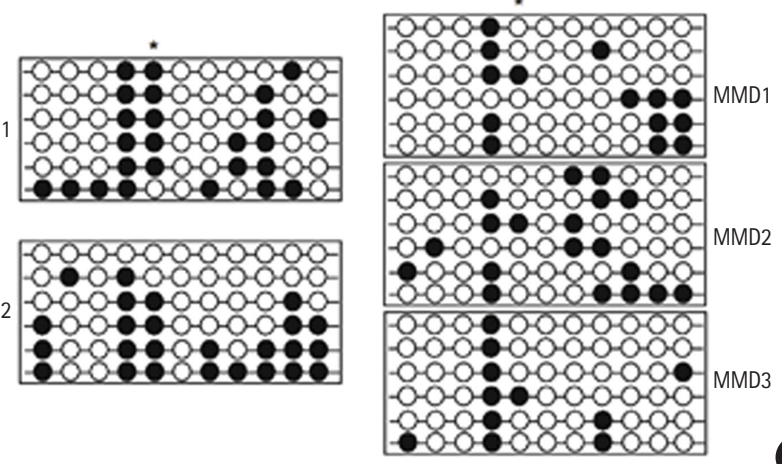

(D)

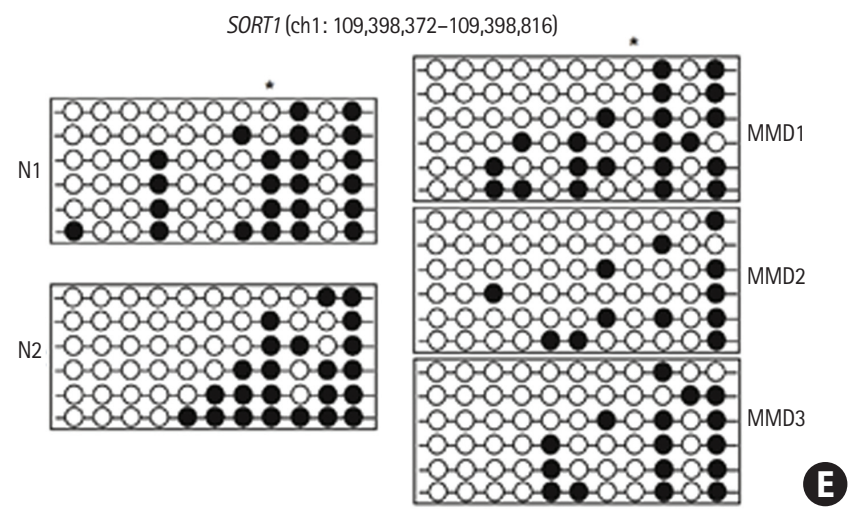

Figure 2. Promoter $\mathrm{CpG}$ sites in the five candidate genes were hypomethylated in endothelial colony forming cells (ECFCs) from patients with moyamoya disease (MMD). The DNA methylation status within the promoter region was analyzed using bisulfite sequencing polymerase chain reaction. Each circle represents $\mathrm{CpG}$ dinucleotides. The methylation status of each $\mathrm{CpG}$ site is denoted by black (methylated) or white (unmethylated) circles. Stars above the circles indicate the differentially methylated $\mathrm{CpG}$ sites in ECFCs, as revealed by DNA methylation microarray analysis. (A) Apolipoprotein D (APOD), (B) fibroblast activation protein alpha (FAP), (C) lipopolysacchride induced tumor necrosis factor-alpha factor (LITAP), (D) nuclear protein 1 (NUPR1), and (E) sortilin 1 (SORT1). N, normal control.

moter $\mathrm{CpG}$ sites and downregulated ( $\mathrm{FC}>1.5)$ by hypermethylation $(\Delta \beta>0.2)$ at promoter $\mathrm{CpG}$ sites in ECFCs from patients with MMD compared to normal control ECFCs. Using these criteria, five candidate genes were selected. All five genes were upregulated via promoter $\mathrm{CpG}$ hypomethylation (Table 1).

Candidate gene expression was upregulated in ECFCs from patients with MMD

mRNA of the five candidate genes were validated by RT-qPCR.
Expression of all five genes were increased in the ECFCs of the three patients with MMD compared to those of the two controls (Figure 1).

Candidate gene expression was regulated by DNA methylation

Apolipoprotein D (APOD) promoter CpG sites (human GRCh38/ hg38 assembly position 195,583,895-195,583,362, chromosome 3)-especially the first through the fourth CpGs-were hypo- 
$A P O D$

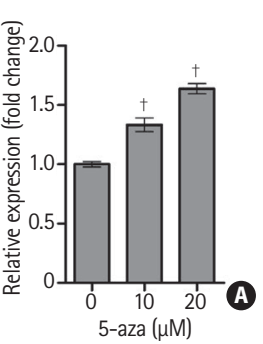

NUPR1

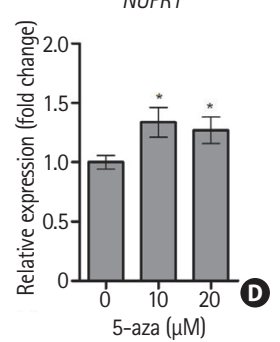

FAP

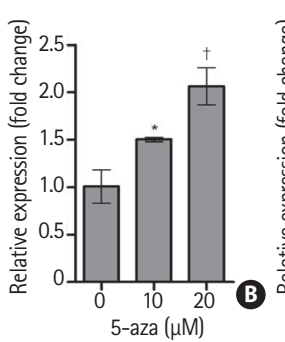

SORT1

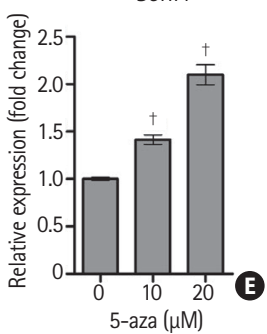

LITAF

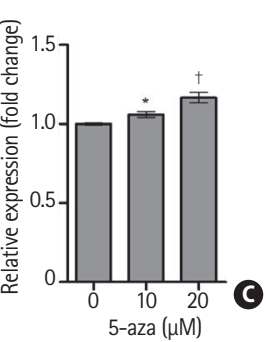

$A P O D$

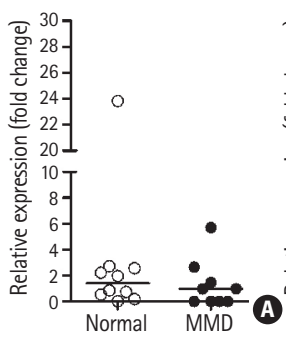

NUPR1
FAP
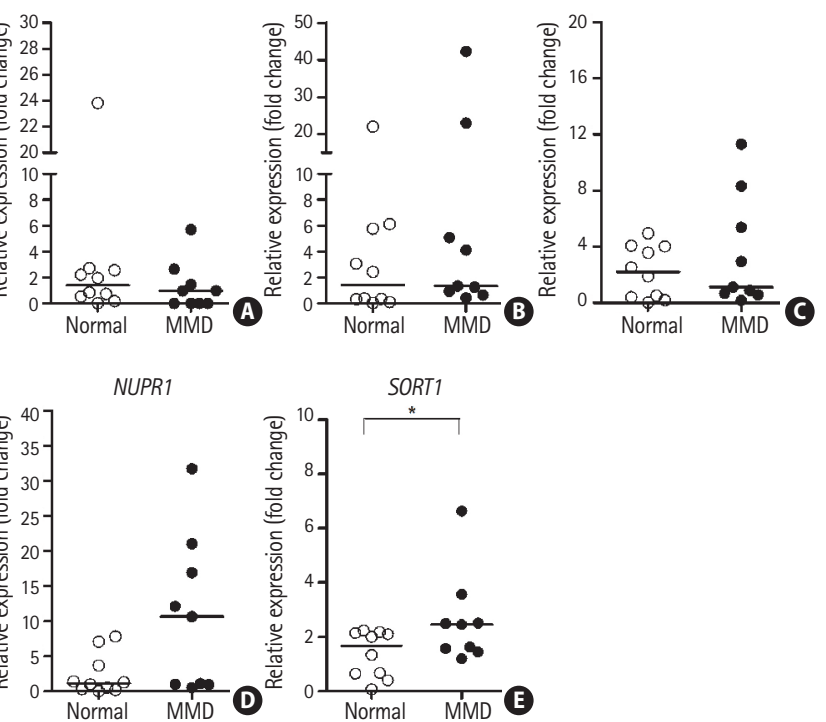

Figure 3. Transcriptional expression of the five candidate genes altered by a DNA methyltransferase inhibitor. Endothelial colony forming cells from normal control N1 were treated with 0, 10, and $20 \mu \mathrm{M}$ 5-aza-2'-deoxycytidine for 3 days. After treatment with 5-aza-2'-deoxycytidine, mRNA expression was determined by reverse transcription-quantitative polymerase chain reaction. Data are represented as mean \pm standard deviation $(n=3)$. Statistical analyses were performed using a one-way analysis of variance and Dunnett's multiple comparison post-tests for comparing treated and untreated cells. (A) Apolipoprotein D (APOD), (B) fibroblast activation protein alpha $(F A P)$, (C) lipopolysacchride induced tumor necrosis factor-alpha factor (LITAF), (D) nuclear protein 1 (NUPR1), and (E) sortilin 1 (SORT1). $\mathrm{N}_{\text {, }}$ normal control. ${ }^{*} P<0.05 ;{ }^{+} P<0.001$.

methylated in ECFCs from all three patients with MMD relative to those from the two normal controls. Six out of seven $\mathrm{CpG}$ sites in the fibroblast activation protein alpha (FAP) promoter region (162,243,202-162,243,697, chromosome 2) were hypomethylated in ECFCs from patients with MMD. Lipopolysacchride induced tumor necrosis factor-alpha factor (LITAP) promoter region (11,587,448-11,587,875 of chromosome 16) CpG sites (especially the fourth and fifth) were mainly hypomethylated in ECFCs from patients with MMD. Obvious hypomethylation was observed at the fifth $\mathrm{CpG}$ site within the nuclear protein 1 (NUPR1) promoter region located at 28,538,953-28,539,381 of chromosome 16. In the SORT1 promoter region $(109,398,372-$ $109,398,816$ of chromosome 1), which contains 11 CpG sites, the eighth $\mathrm{CpG}$ site was unmethylated in ECFCs from all three patients with MMD while it was heavily methylated in ECFCs from normal controls (Figure 2). These results are consistent with the results of our DNA methylation microarray.

After ECFCs from a normal control (N1) were treated with 5-aza-dC, a DNA methyltransferase inhibitor, transcriptional expression of all five candidate genes was significantly increased (Figure 3). mRNA expression of FAP and SORT1 was
Figure 4. mRNA expression of sortilin 1 (SORT1) was upregulated in patients with moyamoya disease (MMD). mRNA expression of the five candidate genes in endothelial colony forming cells was determined via reverse transcription-quantitative polymerase chain reaction for nine patients with $\mathrm{MMD}$ and ten controls. The lines inside the graphs represent medians. Statistical analyses were performed using the Mann-Whitney U test. (A) Apolipoprotein $D(A P O D)$, $(B)$ fibroblast activation protein alpha (FAP), (C) lipopolysacchride induced tumor necrosis factor-alpha factor (LITAF), (D) nuclear protein 1 (NUPR1), and (E) SORT1. ${ }^{*} P<0.05$.

upregulated approximately two-fold when cells were treated with $20 \mu \mathrm{M}$ of 5-aza-dC. These results indicate that transcriptional expression of the five candidate genes was epigenetically regulated by DNA methylation.

\section{SORT1 promoter $\mathrm{CpG}$ site was hypomethylated in patients with MMD}

We investigated the mRNA expression levels of five candidate genes in ECFCs from nine patients with MMD and 10 normal controls for further validation of our previous results. Only SORT1 mRNA expression was significantly upregulated in ECFCs from patients with MMD compared to those of normal controls (Figure 4). However, we only had a $48 \%$ detection power (at $P=0.05$ ) for detecting a significant mean difference in SORT1 mRNA expression between the two groups. This indicates that the sample size used for these an alysis was not sufficient to detect MMDrelated differences (Supplementary Figure 1A).

We further examined the DNA methylation status of specific promoter $\mathrm{CpG}$ sites for five candidate genes in ECFCs from eight patients with MMD and eight normal controls using pyrosequencing (specific $\mathrm{CpGs}$ are listed in Supplementary Table 4). Among the five candidate genes, only the specific promoter CpG site on SORT1 was significantly hypomethylated in ECFCs 

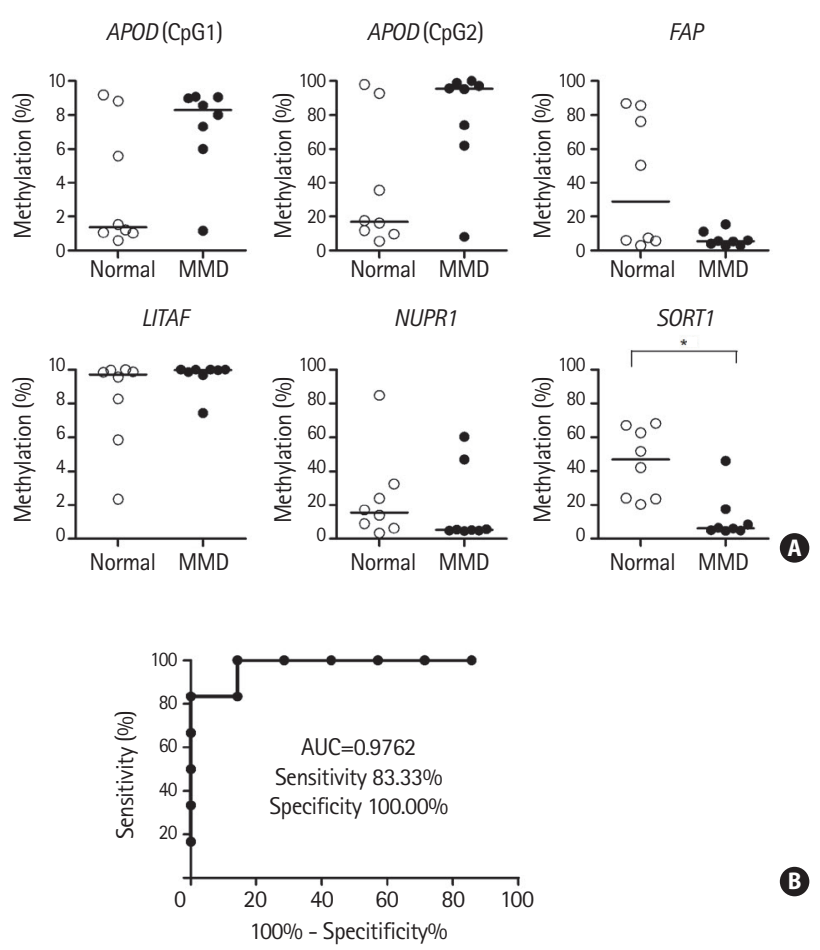

B

Figure 5. Evaluation of DNA methylation status at a specific sortilin 1 (SORT1) promoter $\mathrm{CpG}$ site as an moyamoya disease (MMD) biomarker. (A) DNA methylation status at the specific promoter $\mathrm{CpG}$ sites for five candidate genes was determined using pyrosequencing analysis of endothelial colony forming cells (ECFCs) from eight patients with MMD and eight normal controls. Lines inside graphs represent medians. Statistical analyses were performed using the Mann-Whitney $\mathrm{U}$ test. DNA methylation status at specific SORT1 CpG sites was determined using ECFC pyrosequencing analysis from an independent sample set of patients with MMD $(n=7)$ and normal controls $(n=6)$. (B) Receiver operating characteristic curves reveal discrimination of patients with MMD from normal controls based on DNA methylation status at a specific SORT1 promoter CpG site. APOD, apolipoprotein $D ; F A P$, fibroblast activation protein alpha; $L I T A F$, lipopolysacchride induced tumor necrosis factor-alpha factor; NUPR1, nuclear protein $1_{i}$ AUC, area under the curve. ${ }^{*} P<0.01$.

from patients with MMD versus controls (Figure $5 \mathrm{~A}$ ). The power of detecting a significant mean difference in methylation at specific promoter $\mathrm{CpG}$ site on SORT1 between two groups with significance level of 0.05 was $93 \%$. This indicates that the sample size used for the analysis offered sufficient power to detect differences between controls and patients with MMD (Supplementary Figure 1B).

We next evaluated whether MMD can be predicted by DNA methylation status at a specific SORT1 promoter $\mathrm{CpG}$ site using a logistic regression model in a set of independent MMD samples $(n=7)$ and controls $(n=6)$. The sample size used for this analysis offered sufficient power (89\%) to detect differences between normal controls and patients with MMD (Supplementary Figure 1C). A receiver operating characteristic curve analysis revealed good separation of patients with MMD from nor- mal controls with a sensitivity of $83.33 \%$ and a specificity of $100 \%$ (Figure 5B). The area under the curve was 0.9762 $(P=0.004292)$. These results suggest that the DNA methylation status at a specific promoter $\mathrm{CpG}$ site on the SORT1 is a potential biomarker for MMD.

\section{SORT1-inhibited HUVEC tube formation}

To elucidate the functional role of SORT1 in angiogenesis, a SORT1 expression plasmid construct was transiently transfected into HUVECs. HUVEC tube formation was then evaluated using a Matrigel assay. After a 24-hour transfection, overexpression of SORT1 was confirmed by RT-qPCR (Supplementary Figure 2). At 16-hour of tube formation, overexpression of SORT1 suppressed tube length by $70 \% \pm 10.71 \%$ compared to the mock transfected controls (Figure 6A).

We further explored how SORT1 expression affects HUVEC tube formation using siRNA-induced SORT1 knockdown. After a 24-hour transfection, knockdown of endogenous SORT1 expression was confirmed by RT-qPCR. The expression of SORT1 mRNA was reduced by $59 \% \pm 4.25 \%$ in siSORT1-transfected HUVECs versus siNC-mock transfected cells (Supplementary Figure 2). Knockdown of SORT1 expression induced a significant increase $(39 \% \pm 14.76 \%)$ in tube length in HUVECs versus mock transfected controls (Figure 6B).

Finally, we investigated the effect of SORT1 on major angiogenic factor and MMP expression by RT-qPCR in SORT1-overexpressing HUVECs. Expression of MMP9, VEGF, vascular endothelial growth factor receptor 1 (VEGFR1), and FGF2 were significantly increased, while expression of thrombospondin 2 (THBS2) and angiopoietin 1 (ANGPT1) was reduced by approximately $74 \%$ and $76 \%$, respectively, in SORT1-transfected HUVECs versus mock transfected controls (Figure $6 \mathrm{C}$ ). These results indicate that SORT1 overexpression suppressed the angiogenic potential of endothelial cells by modulating their expression of major angiogenic factors and MMPs.

\section{Discussion}

The pathogenesis of MMD still remains poorly understood and no reliable molecular biomarkers for MMD have been identified to date. DNA methylation is a major epigenetic mechanism, with alterations reflecting the pathological development of various diseases such as cancer, neurodegenerative disease, and autoimmune disease. ${ }^{18}$ Alterations in DNA methylation have recently emerged as biomarkers for the detection and/or diagnosis of various diseases due to their stability, frequency, and noninvasive accessibility via bodily fluids such as blood, urine, and CSF. ${ }^{19}$

Here, we performed an integrated analysis of gene expres- 

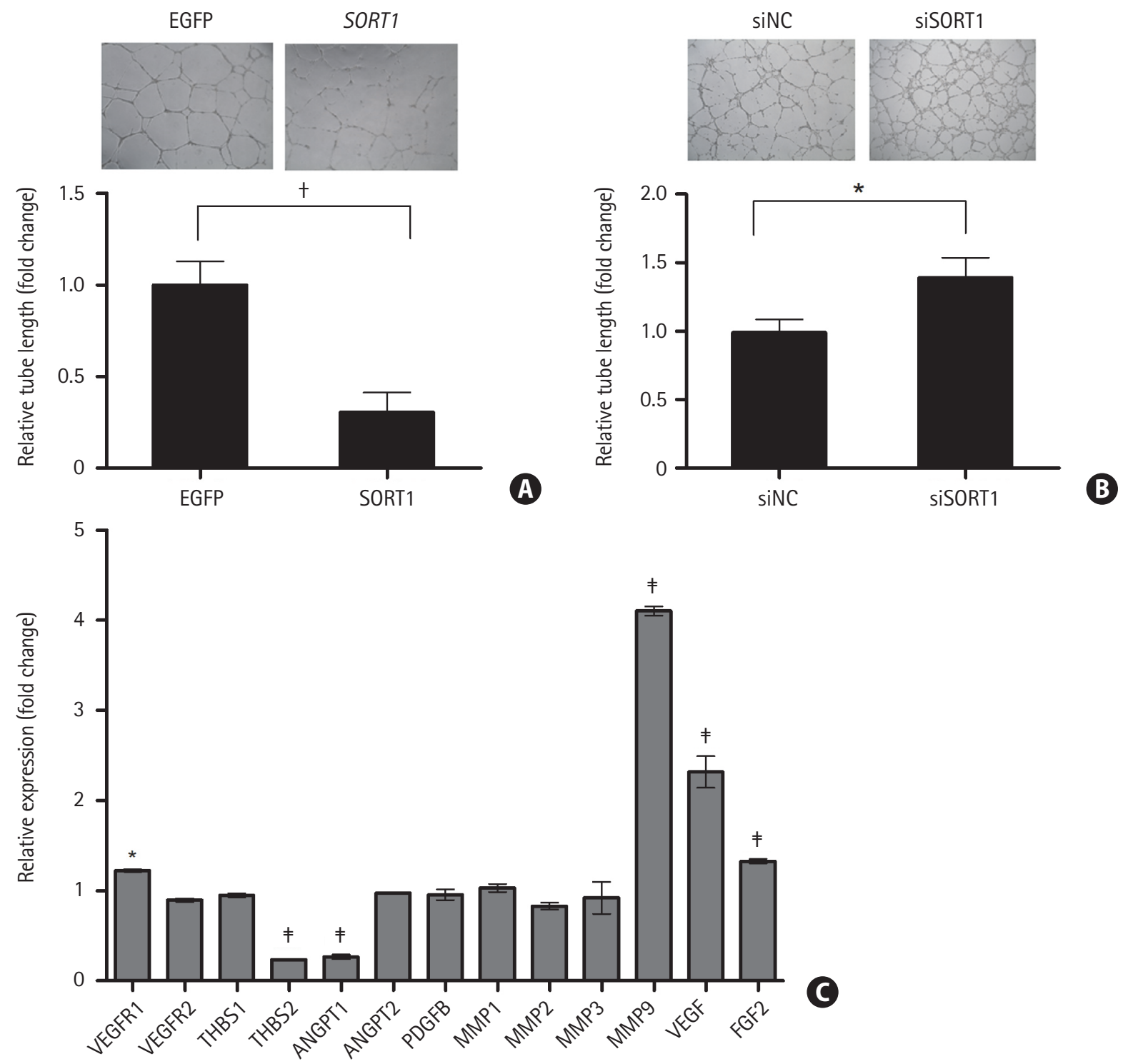

Figure 6. Overexpression of sortilin 1 (SORT1) suppressed human umbilical vein endothelial cell (HUVEC) tube formation. Representative images show tube formation in mock transfected and SORT1-transfected (A, upper panel) or non-targeting control siRNA (siNC) and SORT1 siRNA (siSORT1)-transfected (B, upper panel) HUVECs. Tube length was quantified by Image J software using pictures of tube formation ( $n=6 ; A$ and $B$, lower panel). (C) Comparisons were made via t-tests. mRNA expression of major angiogenic factors and matrix metalloproteinases (MMPs) was determined by reverse transcription-quantitative polymerase chain reaction in mock transfected and SORT1-transfected HUVECs. Data are shown as mean \pm standard deviation ( $n=3$ ). A one-way analysis of variance and Dunnett's multiple comparison post-tests were used to compare mock and SORT1-transfected HUVECs. EGFP, enhanced green fluorescent protein; VEGFR, vascular endothelial growth factor receptor; THBS, thrombospodin; ANGPT, angiopoietin; PDGFB, platelet-derived growth factor subunit B; VEGF, vascular endothelial growth factor; FGF2, fibroblast growth factor $2 .{ }^{*} P<0.05 ;{ }^{+} P<0.01 ;{ }^{*} P<0.001$.

sion and DNA methylation profiles to identify genes associated with MMD using ECFCs from three patients with MMD and two normal controls. Five genes (APOD, FAP, LITAF, NUPR1, SORT1) were selected in an initial evaluation, expression of which was upregulated by hypomethylation of specific promoter $\mathrm{CpG}$ sites. The DNA methylation-dependent transcriptional regulation of the five candidate genes was confirmed by treatment with a DNA methyltransferase inhibitor. Transcriptional expression of these five genes was significantly in- creased after treatment with 5-aza-2'-deoxycytidine. The differential mRNA expression and DNA methylation status at specific promoter $\mathrm{CpG}$ sites for these five genes in ECFCs from patients with MMD and normal controls was further validated in an expanded sample of patients with MMD and normal controls. The statistically significant upregulation of mRNA expression and hypomethylation at specific promoter $\mathrm{CpG}$ sites was only observed in SORT1, which was also used to readily and accurately distinguished patients with MMD from normal con- 
trols (receiver operating characteristic area under the curve 0.98 , sensitivity $83.3 \%$, specificity $100 \%$ ). This was evaluated in an independent sample set of patients with MMD $(n=7)$ and normal controls $(n=6)$ using a logistic regression model.

The SORT1 gene within the $1 \mathrm{p} 13.3$ locus of chromosome 1 encodes the protein sortilin, which is one of five members of the mammalian vacuolar protein sorting 10 protein (VPS10P) domain receptor family. It is produced in the endoplasmic reticulum as a precursor protein harboring a 44-amino acid propeptide, and proteolytically processed by furin-mediated cleavage to generate the mature form of the receptor in late Golgi compartment. This receptor is involved in the trafficking of a wide variety of intracellular proteins to either the cell surface or subcellular compartments, such as endosomes and lysosomes, to mediate endocytosis and lysosomal degradation. ${ }^{20}$ Recently, sortilin was reported to be an important modulator of lipid metabolism and atherogenesis. Prior studies on the overexpression or deficiency of sortilin in atherosclerotic mouse models suggested that sortilin strongly affects plasma cholesterol levels and the development of atherosclerosis, though its role in the export of hepatic lipoproteins remains controversial. A study reported that an absence of sortilin in an atherosclerotic mouse model resulted in decreased plasma low density lipoprotein cholesterol (LDL-C) levels and aortic atherosclerotic lesions, indicating that sortilin is involved in lipid metabolism and atherosclerosis. ${ }^{21}$ Other studies have reported that sortilin knockdown in the mouse liver increases plasma cholesterol levels. ${ }^{22,23}$ Human genome-wide association studies have also shown that overexpression of SORT1 leads to decreased plasma LDL-C levels and deficiency of SORT1 results in increased plasma cholesterol levels. ${ }^{24,25}$

Further studies are required to determine the regulatory mechanisms of sortilin in lipid metabolism; sortilin also acts as a neurotransmitter receptor to regulate pro-nerve growth factor (proNGF)-induced neuronal viability and function. ${ }^{26} \mathrm{In}$ creasing evidence suggests that sortilin is closely associated with neurodegenerative processes via control of proNGF-induced neuronal death ${ }^{27}$ and alterations to amyloid precursor protein processing caused by $\beta$-secretase trafficking, as in Alzheimer's disease. ${ }^{28}$ Sortilin may perform more functions in different cell-types and tissues. Here, we demonstrate that sortilin is involved in angiogenesis.

Our results show that overexpression of SORT1 suppressed endothelial cell tube formation by modulating the expression of angiogenic factors and MMP9. The expression of pro-angiogenic factors (e.g., VEGF, VEGFR1, and FGF2) was increased, whereas the expression of ANGPT1, which is involved in maturation and stabilization of the developing vasculature by interaction with Tie2 receptor, ${ }_{1}^{29}$ was significantly decreased by the overexpression of SORT1. In addition to pro-angiogenic factors, the expression of THBS2, an endogenous inhibitor of angiogenesis $^{30}$ decreased, while MMP9 expression markedly increased on overexpression of SORT1.

MMP9 promotes angiogenesis by releasing and activating growth factors and cytokines, but also inhibits angiogenesis by generating angiogenic inhibitors, such as angiostatin, and cleaving angiogenic factors. ${ }^{31}$ Angiogenesis is a complex process that involves a dynamic interplay between a multitude of pro- and anti-angiogenic factors. The expressional modulation of angiogenic factors by SORT1 may contribute to abnormal blood vessel development by perturbing the delicate balance between pro- and anti-angiogenic factors. We previously reported increased MMP9 levels in combination with VEGF in plasma from patients with MMD; these may contribute to the intimal hyperplasia and formation of collateral vessels observed in MMD pathology. ${ }^{3}$ Previous studies have also shown elevated levels of FGF2 in the CSF, superficial temporal arteries, and dura mater of patients with MMD, demonstrating that FGF2 may play a major role in the pathogenesis of MMD. ${ }^{8,32} \mathrm{Al}-$ though the precise mechanisms underlying SORT1 modulation of major angiogenic factor expression require further investigation, these results suggest that aberrant overexpression of SORT1, mediated by DNA methylation-dependent transcriptional regulation, contributes to the pathogenesis of MMD.

\section{Conclusions}

Our findings suggest that the DNA methylation status of a specific SORT1 promoter $\mathrm{CpG}$ site in ECFCs may serve as a reliable, noninvasive biomarker for MMD.

\section{Supplementary materials}

Supplementary materials related to this article can be found online at https://doi.org/10.5853/jos.2018.00962.

\section{Disclosure}

The authors have no financial conflicts of interest.

\section{Acknowledgments}

This research was supported by a grant from the Korea Health Technology R\&D Project through the Korea Health Industry Development Institute (KHIDI), funded by the Ministry of Health and Welfare, Republic of Korea (grant number: HI12C0066) and by the National Research Foundation of Korea (NRF) Basic 
Science Research Program, funded by the Ministry of Science, ICT \& Future Planning (2010-0027945).

\section{References}

1. Scott RM, Smith ER. Moyamoya disease and moyamoya syndrome. N Engl J Med 2009;360:1226-1237.

2. Suzuki J, Takaku A. Cerebrovascular "moyamoya" disease. Disease showing abnormal net-like vessels in base of brain. Arch Neurol 1969;20:288-299.

3. Kang HS, Kim JH, Phi JH, Kim YY, Kim JE, Wang KC, et al. Plasma matrix metalloproteinases, cytokines and angiogenic factors in moyamoya disease. J Neurol Neurosurg Psychiatry 2010;81:673-678.

4. Zhao S, Gong Z, Zhang J, Xu X, Liu P, Guan W, et al. Elevated serum microRNA Let-7c in moyamoya disease. J Stroke Cerebrovasc Dis 2015;24:1709-1714.

5. Amano $T$, Inoha $S$, Wu CM, Matsushima T, Ikezaki K. Serum alpha1-antitrypsin level and phenotype associated with familial moyamoya disease. Childs Nerv Syst 2003;19:655-658.

6. Fujimura $M$, Watanabe $M$, Narisawa $A$, Shimizu $H$, Tominaga $T$. Increased expression of serum matrix metalloproteinase-9 in patients with moyamoya disease. Surg Neuro/ 2009;72:476480.

7. Kim SK, Yoo Jl, Cho BK, Hong SJ, Kim YK, Moon JA, et al. Elevation of CRABP-I in the cerebrospinal fluid of patients with moyamoya disease. Stroke 2003;34:2835-2841.

8. Takahashi A, Sawamura Y, Houkin K, Kamiyama H, Abe H. The cerebrospinal fluid in patients with moyamoya disease (spontaneous occlusion of the circle of Willis) contains high level of basic fibroblast growth factor. Neurosci Lett 1993; 160:214-216

9. Soriano SG, Cowan DB, Proctor MR, Scott RM. Levels of soluble adhesion molecules are elevated in the cerebrospinal fluid of children with moyamoya syndrome. Neurosurgery 2002;50:544-549.

10. Ni G, Liu W, Huang $X$, Zhu S, Yue $X$, Chen $Z$, et al. Increased levels of circulating SDF-1alpha and CD34+ CXCR4+ cells in patients with moyamoya disease. Eur J Neurol 2011;18:13041309.

11. Jung KH, Chu K, Lee ST, Park HK, Kim DH, Kim JH, et al. Circulating endothelial progenitor cells as a pathogenetic marker of moyamoya disease. J Cereb Blood Flow Metab 2008;28: 1795-1803.

12. Kang HS, Moon YJ, Kim YY, Park WY, Park AK, Wang KC, et al. Smooth-muscle progenitor cells isolated from patients with moyamoya disease: novel experimental cell model. J Neurosurg 2014;120:415-425.
13. Fujimura $M$, Sonobe $S$, Nishijima $Y$, Niizuma $K$, Sakata $H$, Kure $S$, et al. Genetics and biomarkers of moyamoya disease: significance of RNF213 as a susceptibility gene. J Stroke 2014;16:65-72.

14. Kim JH, Jung JH, Phi JH, Kang HS, Kim JE, Chae JH, et al. Decreased level and defective function of circulating endothelial progenitor cells in children with moyamoya disease. $J$ Neurosci Res 2010;88:510-518.

15. Park JH, Jin YM, Hwang $\mathrm{S}$, Cho DH, Kang DH, Jo I. Uric acid attenuates nitric oxide production by decreasing the interaction between endothelial nitric oxide synthase and calmodulin in human umbilical vein endothelial cells: a mechanism for uric acid-induced cardiovascular disease development. Nitric Oxide 2013;32:36-42.

16. Smyth GK. Linear models and empirical bayes methods for assessing differential expression in microarray experiments. Stat Appl Genet Mol Biol 2004;3:Article3.

17. Teschendorff AE, Marabita F, Lechner M, Bartlett $T$, Tegner J, Gomez-Cabrero $D$, et al. A beta-mixture quantile normalization method for correcting probe design bias in Illumina Infinium 450 k DNA methylation data. Bioinformatics 2013; 29:189-196.

18. García-Giménez JL, Sanchis-Gomar F, Lippi G, Mena S, Ivars D, Gomez-Cabrera MC, et al. Epigenetic biomarkers: a new perspective in laboratory diagnostics. Clin Chim Acta 2012; 413:1576-1582.

19. Leygo $C$, Williams $M$, Jin HC, Chan MWY, Chu WK, Grusch $M$, et al. DNA methylation as a noninvasive epigenetic biomarker for the detection of cancer. Dis Markers 2017;2017:3726595.

20. Zhong LY, Cayabyab FS, Tang CK, Zheng XL, Peng TH, Lv YC. Sortilin: a novel regulator in lipid metabolism and atherogenesis. Clin Chim Acta 2016;460:11-17.

21. Kjolby $M$, Andersen $O M$, Breiderhoff T, Fjorback AW, Pedersen KM, Madsen $P$, et al. Sort1, encoded by the cardiovascular risk locus 1p13.3, is a regulator of hepatic lipoprotein export. Cell Metab 2010;12:213-223.

22. Musunuru K, Strong A, Frank-Kamenetsky M, Lee NE, Ahfeldt T, Sachs KV, et al. From noncoding variant to phenotype via SORT1 at the 1p13 cholesterol locus. Nature 2010;466:714719.

23. Linsel-Nitschke $P$, Heeren J, Aherrahrou Z, Bruse P, Gieger $C$, Illig T, et al. Genetic variation at chromosome 1p13.3 affects sortilin mRNA expression, cellular LDL-uptake and serum LDL levels which translates to the risk of coronary artery disease. Atherosclerosis 2010;208:183-189.

24. Strong A. Sortilin as a novel regulator of plasma cholesterol, very-low density lipoprotein secretion and LDL catabolism [dissertation]. Philadelphia (PA): University of Pennsylvania; 
2012.

25. Calkin AC, Tontonoz P. Genome-wide association studies identify new targets in cardiovascular disease. Sci Transl Med 2010;2:48ps46.

26. Nykjaer $A$, Willnow TE. Sortilin: a receptor to regulate neuronal viability and function. Trends Neurosci 2012;35:261-270.

27. Mufson EJ, Wuu J, Counts SE, Nykjaer A. Preservation of cortical sortilin protein levels in $\mathrm{MCl}$ and Alzheimer's disease. Neurosci Lett 2010;471:129-133.

28. Finan $\mathrm{GM}, \mathrm{Okada} \mathrm{H}, \mathrm{Kim}$ TW. BACE1 retrograde trafficking is uniquely regulated by the cytoplasmic domain of sortilin. $J$ Biol Chem 2011;286:12602-12616.

29. Distler JH, Hirth A, Kurowska-Stolarska M, Gay RE, Gay S,
Distler 0. Angiogenic and angiostatic factors in the molecular control of angiogenesis. Q J Nucl Med 2003;47:149-161.

30. Lawler PR, Lawler J. Molecular basis for the regulation of angiogenesis by thrombospondin-1 and -2 . Cold Spring Harb Perspect Med 2012;2:a006627.

31. Cornelius LA, Nehring LC, Harding E, Bolanowski M, Welgus $H G$, Kobayashi DK, et al. Matrix metalloproteinases generate angiostatin: effects on neovascularization. J Immunol 1998; 161:6845-6852.

32. Hoshimaru M, Takahashi JA, Kikuchi H, Nagata I, Hatanaka $M$. Possible roles of basic fibroblast growth factor in the pathogenesis of moyamoya disease: an immunohistochemical study. J Neurosurg 1991;75:267-270. 
Supplementary Table 1. Demographic information of moyamoya disease patients and normal controls

\begin{tabular}{|c|c|c|c|c|c|c|c|}
\hline Case no. & Sex & Age (yr) & Symptoms & $\begin{array}{l}\text { Suzuki grade } \\
(r t / / t)\end{array}$ & Infarct & $\begin{array}{c}\text { RNF213 } \\
\text { c. } 14576 G>A \\
\text { variant }\end{array}$ & Use \\
\hline \multicolumn{8}{|c|}{ Moyamoya disease patients } \\
\hline MMD1 & $\mathrm{F}$ & 4 & Headache, TIA (rt) & $2 / 3$ & Borderzone infarct & $\mathrm{G} / \mathrm{A}$ & $E A, M A, R T, B S P$ \\
\hline MMD2 & $\mathrm{F}$ & 17 & $\mathrm{TIA}(\mathrm{It})$ & $3 / 2$ & None & $\mathrm{A} / \mathrm{A}$ & EA, MA, RT, BSP \\
\hline MMD3 & M & 6 & $\mathrm{TIA}(\mathrm{It})$ & $3 / 2$ & None & $\mathrm{G} / \mathrm{A}$ & $E A, M A, R T, B S P$ \\
\hline MMD4 & M & 1 & $\begin{array}{l}\text { Seizure, hemiparesis } \\
(\mathrm{rt})\end{array}$ & $2 / 3$ & Lobar infarct & $\mathrm{G} / \mathrm{G}$ & RT, PS1 \\
\hline MMD5 & $\mathrm{F}$ & 10 & $\begin{array}{l}\text { Headache, involuntary } \\
\text { movement (It) }\end{array}$ & $3 / 4$ & Lobar infarct & $\mathrm{G} / \mathrm{G}$ & RT, PS1 \\
\hline MMD6 & M & 1 & Seizure, hemiparesis (It) & $2 / 2$ & $\begin{array}{l}\text { Lobar infarct, chronic } \\
\text { infarct }\end{array}$ & $\mathrm{G} / \mathrm{G}$ & RT, PS1 \\
\hline MMD7 & $\mathrm{F}$ & 8 & $\mathrm{TIA}(\mathrm{rt})$ & $3 / 2$ & None & $\mathrm{G} / \mathrm{A}$ & RT, PS1 \\
\hline MMD8 & $\mathrm{F}$ & 13 & Headache & $2 / 2$ & None & $\mathrm{G} / \mathrm{G}$ & RT, PS2 \\
\hline MMD9 & $\mathrm{F}$ & 11 & $\begin{array}{c}\text { Headache, lower ex- } \\
\text { tremity TIA (both) }\end{array}$ & $4 / 4$ & Borderzone infarct & $\mathrm{G} / \mathrm{A}$ & RT, PS2 \\
\hline MMD10 & $\mathrm{F}$ & 14 & $\mathrm{TIA}(\mathrm{It})$ & $4 / 3$ & None & $\mathrm{G} / \mathrm{A}$ & RT, PS1 \\
\hline MMD11 & $\mathrm{F}$ & 10 & $\mathrm{TIA}(\mathrm{rt})$ & $4 / 4$ & None & $\mathrm{G} / \mathrm{A}$ & $\mathrm{RT}, \mathrm{PS} 1$ \\
\hline MMD12 & M & 7 & Headache, TIA (It) & $3 / 3$ & None & $\mathrm{G} / \mathrm{G}$ & PS1 \\
\hline MMD13 & M & 6 & $\mathrm{TIA}(\mathrm{rt})$ & $1 / 3$ & Hemorrhagic infarct & $\mathrm{G} / \mathrm{G}$ & PS1 \\
\hline MMD14 & M & 5 & $\mathrm{TIA}(\mathrm{It})$ & $3 / 2$ & None & $\mathrm{G} / \mathrm{A}$ & PS2 \\
\hline MMD15 & $M$ & 9 & Hemiparesis (It) & $3 / 3$ & Lobar infarct & $\mathrm{G} / \mathrm{A}$ & PS2 \\
\hline MMD16 & $\mathrm{F}$ & 4 & $\mathrm{TIA}(\mathrm{It})$ & $3 / 2$ & None & $\mathrm{G} / \mathrm{G}$ & PS2 \\
\hline MMD17 & M & 8 & $\mathrm{TIA}(\mathrm{rt})$ & $1 / 3$ & None & $\mathrm{G} / \mathrm{G}$ & PS2 \\
\hline MMD18 & $\mathrm{F}$ & 4 & Hemiparesis (rt) & $2 / 4$ & Lobar infarct & $\mathrm{G} / \mathrm{G}$ & PS2 \\
\hline \multicolumn{8}{|c|}{ Normal controls } \\
\hline N1 & $\mathrm{F}$ & 23 & & & & $\mathrm{G} / \mathrm{G}$ & $E A, M A, R T, B S P$ \\
\hline N2 & $M$ & 21 & & & & $\mathrm{G} / \mathrm{G}$ & EA, MA, RT, BSP, PS1 \\
\hline N3 & M & 28 & & & & $\mathrm{G} / \mathrm{G}$ & RT \\
\hline N4 & $\mathrm{F}$ & 23 & & & & $\mathrm{G} / \mathrm{G}$ & RT, PS2 \\
\hline N5 & M & 24 & & & & $\mathrm{G} / \mathrm{G}$ & RT, PS1 \\
\hline N6 & M & 24 & & & & G/G & RT, PS1 \\
\hline N7 & $F$ & 26 & & & & $\mathrm{G} / \mathrm{G}$ & RT, PS1 \\
\hline N8 & $M$ & 25 & & & & $\mathrm{G} / \mathrm{G}$ & RT, PS1 \\
\hline N9 & $M$ & 24 & & & & $\mathrm{G} / \mathrm{G}$ & $\mathrm{RT}, \mathrm{PS} 1$ \\
\hline N10 & $M$ & 20 & & & & $\mathrm{G} / \mathrm{A}$ & RT, PS1 \\
\hline N11 & $M$ & 22 & & & & $\mathrm{G} / \mathrm{G}$ & RT, PS1 \\
\hline $\mathrm{N} 12$ & $\mathrm{~F}$ & 24 & & & & $\mathrm{G} / \mathrm{G}$ & PS2 \\
\hline N13 & $\mathrm{F}$ & 25 & & & & $\mathrm{G} / \mathrm{G}$ & PS2 \\
\hline N14 & M & 25 & & & & $\mathrm{G} / \mathrm{G}$ & PS2 \\
\hline N15 & $M$ & 25 & & & & $\mathrm{G} / \mathrm{G}$ & PS2 \\
\hline N16 & $\mathrm{F}$ & 22 & & & & $\mathrm{G} / \mathrm{G}$ & PS2 \\
\hline
\end{tabular}

rt, right; It, left; RNF213, ring finger protein 213; MMD, moyamoya disease; TIA, transient ischemic attack; G/A, heterozygote (genotype GA); $A / A$, homozygote (genotype $\mathrm{AA}$ ); G/G, wild type (genotype $\mathrm{GG}$ ); EA, expression array; $\mathrm{MA}$, methylation array; RT, reverse-transcription quantitative polymerase chain reaction; BSP, bisulfite sequencing PCR; PS1, pyrosequencing analysis for validation of methylation status on the five candidate; PS2, pyrosequencing analysis for evaluation diagnostic ability of methylation status on SORT1 gene as a biomarker for MMD; N, normal control. 
Supplementary Table 2. List of primers used for reverse-transcription quantitative polymerase chain reaction

\begin{tabular}{|c|c|c|}
\hline Gene & Forward sequence (5'- 3') & Reverse sequence (5'- $\left.3^{\prime}\right)$ \\
\hline$A P O D$ & GCATCCAGGCCAACTACTCACT & GCTTCACCTTCGATTGATTCAC \\
\hline FAP & АССTCTGCTGTGCTTGCCTTA & ССTCAGTGTGAGTGCTCTCATTG \\
\hline LITAF & СATCCCCTTCTGCGTGGAT & AAGCTGGATGAGAGGTGGAAAG \\
\hline NUPR1 & TCCTACCTCGGGCCTCTCAT & стTCTCTCTTGGTGCGACCTTा \\
\hline SORT1 & CCGGGTCCGGGACTTC & GCTATCTCCAACCCAGGACAAG \\
\hline VEGFR1 & GAAAACGCATAATCTGGGACAGT & GCGTGGTGTGCTTATTTGGA \\
\hline VEGFR2 & AACGTGTCACTTTGTGCAAGA & TTCCATGAGACGGACTCAGAA \\
\hline THBS1 & TGCTATCACAACGGAGTTCAGT & GCAGGACACCTTITGCAGATG \\
\hline THBS2 & GACACGCTGGATCTCACCTAC & GAAGCTGTCTATGAGGTCGCA \\
\hline ANGPT1 & AGAACCTTCAAGGCTTGGTA & GGTGGTAGCTCTGTTIAATGCT \\
\hline ANGPT2 & ACCCCACTGTTGCTAAAGAAGA & CCATCCTCACGTCGCTGAATA \\
\hline PDGFB & CTCGATCCGCTCCTTIGATGA & CGTTGGTGCGGTCTATGAG \\
\hline$M M P 1$ & AAAATTACACGCCAGATTTGCC & GGTGTGACATTACTCCAGAGTTG \\
\hline MMP2 & GATACCCCTTTGACGGTAAGGA & ССТTCTCCCAAGGTCCATAGC \\
\hline MMP3 & CTGGACTCCGACACTCTGGA & CAGGAAAGGTTCTGAAGTGACC \\
\hline MMP9 & TGTACCGCTATGGTTACACTCG & GGCAGGGACAGTTGCTTCT \\
\hline VEGF & AGGGCAGAATCATCACGAAGT & AGGGTCTCGATGGATGGCA \\
\hline FGF2 & AGGGCAGAATCATCACGAAGT & CGGTTAGCACACACTCCTTGG \\
\hline GAPDH & ААТСССАТСАССАТСТТССА & TGGACTCCACGACGT ACTCA \\
\hline
\end{tabular}

$A P O D$, apolipoprotein $D ; F A P$, fibroblast activation protein alpha; $L I T A F$, lipopolysacchride induced tumor necrosis factor-alpha factor; NUPR1, nuclear protein 1; SORT1, sortilin 1; VEGFR, vascular endothelial growth factor receptor; THBS, thrombospodin; ANGPT, angiopoietin; PDGFB, platelet derived growth factor subunit B; MMP, matrix metalloproteinase; VEGF, vascular endothelial growth factor; FGF2, fibroblast growth factor 2; GAPDH, glyceraldehyde 3-phosphate dehydrogenase. 
Supplementary Table 3. List of primers used for bisulfite sequencing polymerase chain reaction

\begin{tabular}{|c|c|c|}
\hline Gene & Sequences $\left(5^{\prime}-3^{\prime}\right)$ & Strand \\
\hline$A P O D$ & AGGTAGTITTAGATGTAGAATTAGT & Forward \\
\hline$A P O D$ & AAATATTAAAAACATATTACAACAC & Reverse \\
\hline FAP & TTATTGAGGAAGTAAATATTTATGTATAAA & Forward \\
\hline FAP & АТССТТСАТТААТТСТАААААААА & Reverse \\
\hline LITAF & GGGTATGTTATTATTIITITGAGTT & Forward \\
\hline LITAF & AАCCACATCATAАTТСТАСССТТT & Reverse \\
\hline NUPR1 & TGTTGTTTTGTTITTGGTTI & Forward \\
\hline NUPR1 & AАTATACTAАTATСССТТСССССТC & Reverse \\
\hline SORT1 & TITGAGTTGTTAAGTGGAAAAGG & Forward \\
\hline SORT1 & ААСАТСАСАТАСТААААССАААСТТАТС & Reverse \\
\hline
\end{tabular}

$A P O D$, apolipoprotein $D ; F A P$, fibroblast activation protein alpha; $L I T A F$, lipopolysacchride induced tumor necrosis factor-alpha factor; NUPR1, nuclear protein 1; SORT1, sortilin 1. 
Supplementary Table 4. List of primers used for pyrosequencing analyses

\begin{tabular}{|c|c|c|}
\hline Gene & & Primer $\left(5^{\prime}-3^{\prime}\right)$ \\
\hline$A P O D$ & Forward & AGATGAAGGTAGTITTAGATGTAGA \\
\hline & Biotinylated-reverse & AATAAACACAACATCCСАТСТTТАТА \\
\hline & Sequencing primer & GTITTGATGTTATTITTATGTAT \\
\hline & Sequences to analyze ${ }^{*}$ & GTAYYGTYGTYGGTTTA \\
\hline & Position & GRCh38/hg38 [chr3:195,584,008-195,584,026] \\
\hline FAP & Forward & TITGGTITTAAATGAATTGTGAGTGAT \\
\hline & Biotinylated-reverse & ACССААТААСТTАСТАAААТААТССТТС \\
\hline & Sequencing primer & ATTाTGTAATTATATTAATATTTG \\
\hline & Sequences to analyze* & TITAYGTTG \\
\hline & Position & GRCh38/hg38 [chr2:162,243,611-162,243,619] \\
\hline LITAF & Forward & GGGAGTGAATTGGGAAGATGGTA \\
\hline & Biotinylated-reverse & AAATAAAACTACTAATTTCСАAАACTТАCT \\
\hline & Sequencing primer & ATAGGTAAGGTTATTAGTG \\
\hline & Sequences to analyze* & ПтGTYGMTTGTGMTITAGGGTGGTYYGTGTYGTA \\
\hline & Position & GRCh38/hg38 [chr16:11,587,597-11,587,635] \\
\hline NUPR1 & Forward & TAGTTGGATATTITIATAGAGGAGGTT \\
\hline & Biotinylated-reverse & АААТССТАССТСТТСССТАСТТ \\
\hline & Sequencing primer & TAGTGGATATTITITATAGAG \\
\hline & Sequences to analyze ${ }^{*}$ & GAGGTTYYGTITIYGGTA \\
\hline & Position & GRCh38/hg38 [chr16:28,539,190-28,539,208] \\
\hline SORT1 & Forward & TTGTAAGAAGGTGAATGAGAATTGATGTG \\
\hline & Biotinylated-reverse & СТTААССТАССТССССТСАА \\
\hline & Sequencing primer & ATTTAAGGAGATAGATATTAGGAT \\
\hline & Sequences to analyze ${ }^{*}$ & ATTYGTGATTITGTAAGTTGAAGAATAGTTITITATAYGTTा \\
\hline & Position & GRCh38/hg38 [chr1:109,398,539-109,398,583] \\
\hline
\end{tabular}

$A P O D$, apolipoprotein $D ; F A P$, fibroblast activation protein alpha; LITAF, lipopolysacchride induced tumor necrosis factor-alpha factor; NUPR1, nuclear protein 1; SORT1, sortilin 1.

*The specific $\mathrm{CpG}$ sites used for data analysis are underlined. 


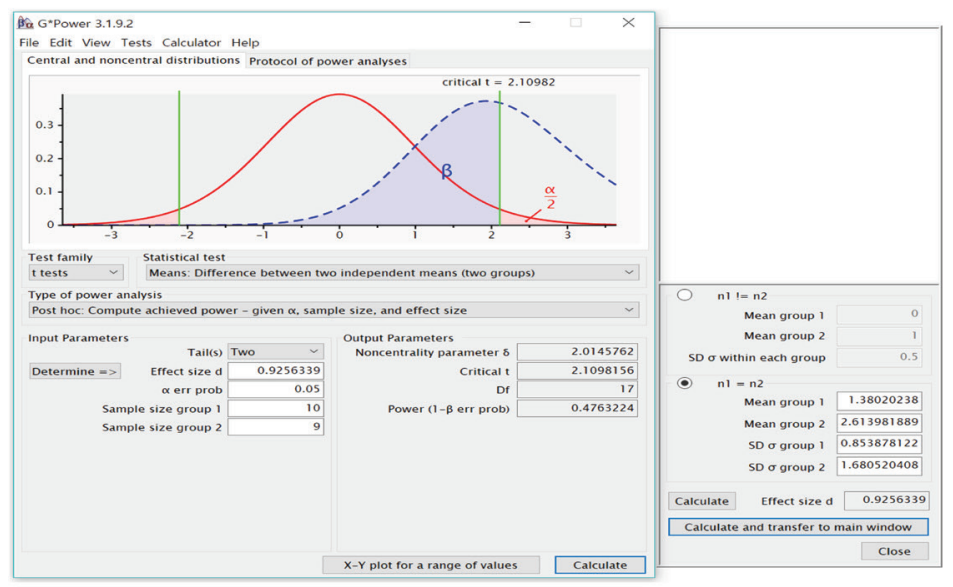

A
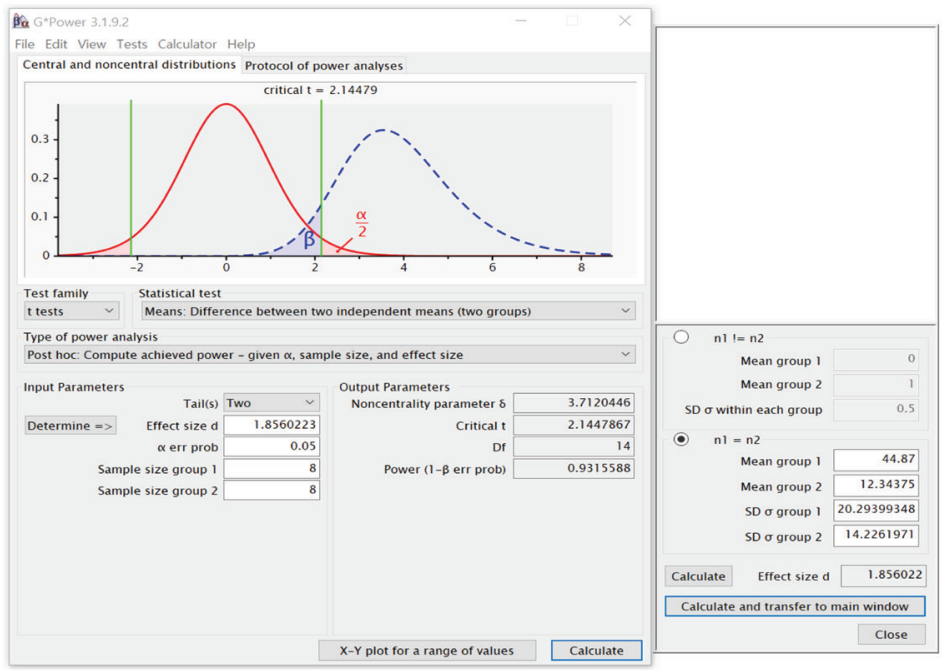

B
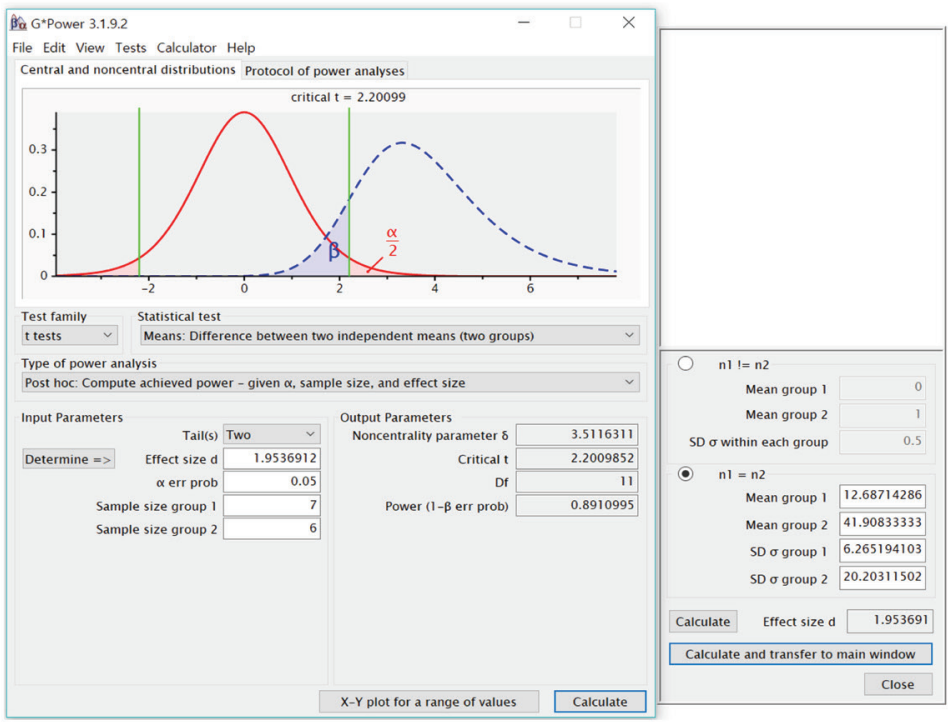

Supplementary Figure 1. The power of detecting a significant mean difference in methylation or mRNA expression of sortilin 1 (SORT1) gene between normal control and moyamoya disease (MMD) groups. To calculate the power to detect a meaningful difference in a given sample size, a post hoc power analysis was performed with $\mathrm{G}^{*}$ power 3.1 software (Heinrich-Heine-University Düsseldorf) using a two-tailed test with the significance level of 0.05 , per convention. (A) A sample set with normal controls $(n=10)$ and MMD patients $(n=8)$ was used for validation of SORT1 mRNA expression in endothelial colony forming cells (ECFCs). (B) A sample set with normal controls $(n=8)$ and MMD patients $(n=8)$ was used for validation of methylation status in the SORT1 promoter in ECFCs. (C) A sample set with normal controls $(n=6)$ and MMD patients $(n=7)$ was used for further validation of methylation status of the SORT1 promoter in ECFCs. 

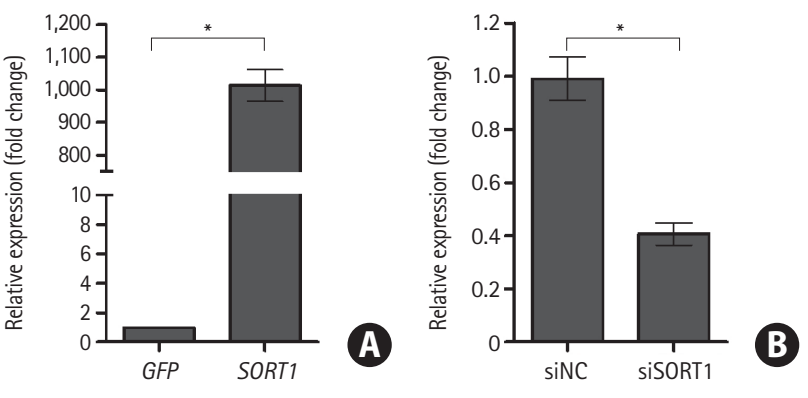

Supplementary Figure 2. Ectopic expression of sortilin 1 (SORT1) mRNA was confirmed by reverse transcription-quantitative polymerase chain reaction (RT-qPCR) following transient transfection. Human umbilical vein endothelial cells were transiently transfected with a pmaxGFP vector and pCMV6-XL5-SORT1 expression construct or with non-targeting control siRNA (siNC) and SORT1 siRNA (siSORT1). Overexpression (A) or depletion (B) of SORT1 mRNA was confirmed via RT-qPCR after a 24-hour transfection. Data are represented as mean \pm standard deviations for the three independent experiments. Statistical differences were determined via t-test. GFP, green fluorescent protein. ${ }^{*} P<0.001$. 